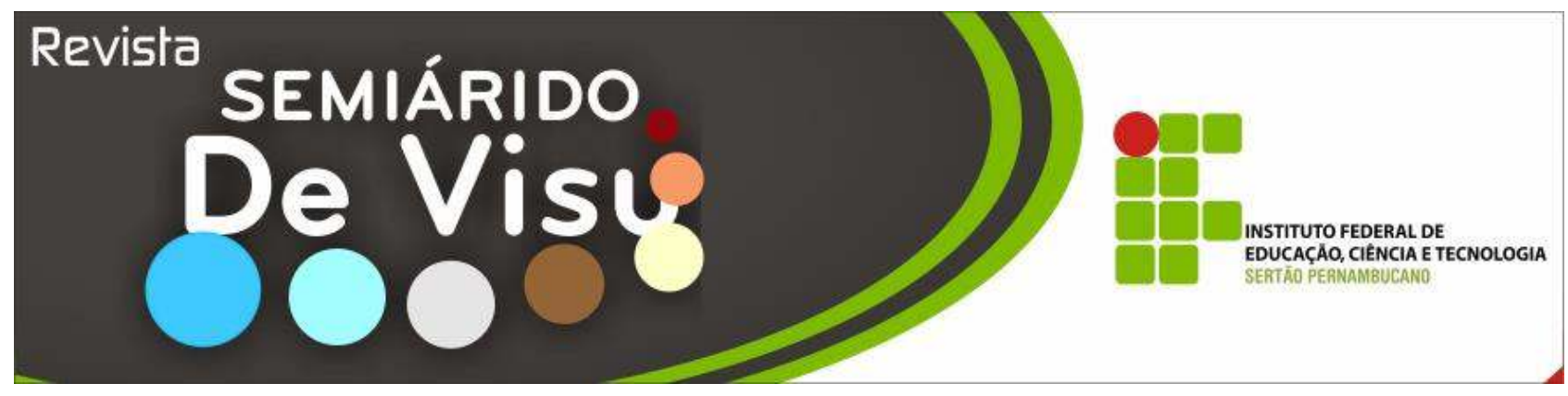

\title{
A comunicação entre ouvintes e pessoas surdas através da Libras nos espaços públicos
}

\author{
Tony Alef de Souza Vasconcelos ${ }^{1}$, Maria Patrícia Lourenço Barros ${ }^{2}$, Aline Cássia Silva Araújo ${ }^{3}$, \\ Antônia Aparecida Barros Alencar Correia ${ }^{4}$
1,2,3,4 Instituto Federal de Educação, Ciências e Tecnologia do Sertão Pernambucano - Campus Salgueiro. BR. 232, Km 508 Sentido Recife, Zona Rural. CEP: 56000-000/ Salgueiro/PE - Brasil/Telefone: (87) 34210050 / E-mail: ${ }^{1}$ tonyc4d@ gmail.com; ${ }^{2}$ patricia.lourenco@ifsertao-pe.edu.br; ${ }^{3}$ aline.araujo@ifsertao-pe.edu.br, ${ }^{4}$ aparecida.barros@ ifsertao-pe.edu.br

\begin{abstract}
RESUMO: Este artigo apresenta resultados da pesquisa interventiva: A comunicação entre ouvintes e pessoas surdas através da Libras nos espaços públicos, os quais mostram que servidores e familiares do Instituto Federal do Sertão Pernambucano - Campus Salgueiro encontram dificuldades na comunicação com surdos. Essa, frequentemente, acontece com auxílio dos intérpretes, tornando-se mais complexa no meio familiar. As inscrições para o curso realizaram-se por editais publicados no site da instituição, tendo como critério de seleção o número de ordem do inscrito. Tal curso realizouse nesse Campus, entre $1^{\circ}$ de julho de 2015 a 30 de junho de 2016, semanalmente, dois encontros de duas horas/aulas. Para isso, elaborou-se questionário e apostila. Dados mostram que 50\% dos servidores possuem contato diário com surdos e os outros $50 \%$, às vezes. Conclui-se que $100 \%$ deles têm ou tiveram contato com surdos, apesar de não saberem efetivamente comunicar-se em Libras. Ratifica-se, então, a necessidade de comunicação com surdos. O auxílio dos intérpretes continua relevante, mas na ausência desses, a comunicação se efetivará mesmo que de forma elementar.
\end{abstract}

Palavras-chave: Libras. Acessibilidade comunicacional. Aprendizagem.

\section{Communication between listeners and deaf people the Libras in public spaces}

\begin{abstract}
This article presents results of the intervention research: A communication between listeners and people about the borders of public spaces, databases and servers of the Federal Institute of Sertão Pernambucano - Campus Salgueiro. This often happens with the help of the interpreters, becoming more complex in the family environment. As enrollments for the course were made by notices published on the institution's website, using as selection criterion or order number of the enrollee. This course was held in this Campus, from July 1, 2015 to June 30, 2016, weekly, two meetings of two hours / classes. For that, a questionnaire and a handout were prepared. Data show that $50 \%$ of the servers are in contact with others and another $50 \%$ at times. It is concluded that $100 \%$ of them have or have contact with the deaf, although they do not know how to effectively communicate in Pounds. It ratifies, then, a necessity of communication with deaf people. The assistance of the interpreters remains relevant, but in his absence, communication is effective even if it is an elementary form.
\end{abstract}

Key words: Libras. Communicational accessibility. Learning 
(VASCONCELOS et al., 2016)

\section{Introdução}

A

inclusão apresenta-se como uma modelo de educação em que todos venham a ter acesso à informação e possam desenvolver a criticidade e a autonomia. Vários órgãos atuam na difusão desse modelo, dentre eles, a escola que se destaca como uma das responsáveis por esse processo, mas ainda encontra dificuldades para se transformar em um ambiente efetivamente inclusivo. Frente a novas políticas de inclusão e a identificação dessa realidade dentro do Instituto Federal do Sertão Pernambucano Campus Salgueiro, é que esse projeto se tornou pertinente ao exercício da cidadania através de uma prática interativa. Prática essa, que possibilitou a comunicação entre pessoas surdas e ouvintes através da Libras por meio de uma proposta de pesquisa subsidiando, principalmente, os servidores da instituição para aprenderem a atender às pessoas surdas usando a Língua Brasileira de Sinais. Assim, Lodi; Lacerda, (2014, p.13), comentam que a Libras:

É a língua, como sistema de signos, que permite a interação entre indivíduos e o partilhar de uma mesma cultura. É também pela linguagem e na linguagem que os conhecimentos são construídos, pois, ao partilharem um sistema de signos constitutivos de uma língua, estes sujeitos podem, além de desenvolverem uma compreensão mútua, colocar em circulação os múltiplos sentidos presentes na linguagem, configurando, assim, a polissemia constitutiva desta. (LODI; LACERDA, 2014, p.13).

No processo de importância da interação através da linguagem é que se percebe o quanto o surdo fica em desvantagem por ser usuário de uma língua que, na maioria dos espaços que ele frequenta, poucas ou quase nenhuma das pessoas conseguem se comunicar usando a Libras. Percebe-se através da fala dos próprios alunos surdos que eles encontram dificuldades para se comunicarem não só na sociedade, como também com os pais e irmãos, pois os familiares também não usam a língua de sinais, o que implica não conseguir entender $\mathrm{e}$ nem ser entendido dentro do próprio ambiente familiar.
As pessoas surdas acabam tendo dificuldades de acesso à linguagem oral e escrita do grupo (ouvinte) ao qual pertencem e, portanto, as práticas educacionais voltadas a essa população devem considerar tal particularidade, o que nem sempre acontece. (LODI; LACERDA, 2014, p.11).

Por este viés é que se vivenciou a pesquisa como uma intervenção após elencar os dados através da realização de cursos para tentar melhorar a comunicação entre ouvintes e surdos da instituição, se estendendo aos servidores, alunos e familiares. A dificuldade de acesso a uma língua acarreta danos não só para os surdos, mas para os ouvintes que convivem com os mesmos e não conseguem entender suas ideias, seus pensamentos, suas vontades e seus desejos. Aprender a se comunicar com as pessoas surdas dentro de um órgão público mostra a responsabilidade que se tem em atender a todos sem ferir seus princípios e, sobretudo, não fingir que os mesmos existem. Em contato com os surdos, constatou-se que os mesmos mostram as dificuldades ao tentarem ir a determinados setores pela falta de comunicação. Conforme Soares (2005, p.17, apud. Werner 1949, p.21), observa-se que um consenso social pessimista, fundamentado essencialmente na ideia de que a condição de 'incapacitado', 'deficiente', 'inválido é uma condução imutável e levou a completa omissão da sociedade em relação à organização de serviços para atender às necessidades individuais específicas dessa população.

Partindo desse pressuposto, precisa-se de uma ruptura onde a vivência deste trabalho, através da própria pessoa surda, possa sensibilizar os ouvintes para que haja mudanças nesta realidade. Por isso, este trabalho teve como bolsista um estudante surdo, que contribuiu com o ensino da língua materna e rompeu alguns paradigmas, através do contato durante as aulas, promovendo a interação entre as duas línguas e entre os dois mundos: o visual e o oral. A Lei 10.436/02 que oficializa a Língua Brasileira de Sinais - Libras - como língua oficial da comunidade surda brasileira ainda passa por grandes dificuldades de efetivação de 
(VASCONCELOS et al., 2016)

uso quanto à garantia aos surdos de poderem usufruir de todas as informações que a Libras dispõe. Como bem afirma Carvalho (2008, p.39):

[...] há algumas décadas assistimos a montagem e a consolidação dos novos impérios econômicos globais que gerenciam a quase totalidade da informação que hoje circula pelo sistema de telefonia, redes de televisão, rádio, redes eletrônicas e satélites. Neste mundo rígido pelas regras e pela retórica do mercado, no qual o consumismo faz parte da cultura, as pessoas em situação de deficiência ficam em maior desvantagem, dentre outras razões, pelo temor de que sejam, apenas, usuárias eternas dos benefícios da assistência social e pouco contributivas para a produção de bens de consumo.

De acordo com a autora acima, a necessidade de informação visual para contemplar a necessidade das pessoas surdas é hoje umas das razões pelas quais os mesmos reivindicam através da lei que oficializa sua língua como forma usual da comunidade surda para que os veículos de comunicação respeitem a lei. Essa Lei vem também reforçar que é chegada a hora de se organizar dentro dos espaços públicos quanto ao conhecimento e aprendizagem da Libras para que se efetive a participação dos mesmos nesses espaços. Sabese que hoje as informações importantes são veiculadas por meio de diversos veículos de comunicação, e o veículo de maior proximidade a população é a televisão. Mas mesmo esse veículo tão popular, ainda não atende à necessidade da comunidade surda, pois nem tudo que é televisionado é traduzido.

Ao pensar neste contexto é que se pode perceber quão significativo é um projeto que estimula o uso da língua e, em especial a Libras, uma vez que demonstra a responsabilidade para promover o envolvimento dos surdos dentro da instituição através de uma comunicação. De acordo com Longman (2007, p.18):

Hoje, grupos surdos, rompendo a ideologia da deficiência biológica, definem-se como minorias lingüísticas. Vêm-se reafirmando como grupos culturais com representações, significações e produções no campo intelectual, ético, estético, artístico e corporal, a partir de sua experiência visual e principalmente, de sua língua, constituída de estratégias cognitivas visuais e corporais.

Esta realidade perpassa pela cidade de Salgueiro-PE, localidade onde os surdos estão inseridos e onde o Instituto Federal de Educação, Ciência e Tecnologia do Sertão Pernambucano - Campus Salgueiro se faz presente. Assim, a chegada dos alunos surdos à instituição só reforça a responsabilidade em busca de alternativas através de projetos que contemplem as questões da surdez e que possa aprender a conviver com a diversidade linguística que passa existir. O IF Campus Salgueiro começou, mesmo que timidamente, a promover no mesmo espaço físico de salas de aula um ensino e aprendizagem na língua portuguesa (oral) e na libras (visual). A vivência do projeto fez com que esta realidade começasse a mudar, quando uma língua começa a ser difundida dentro de um espaço ela começa a se tornar visível e a ser usada, assim os que antes se sentiam isolados por serem únicos usuários da libras começam a ter outros pares para dialogarem e partilharem suas ideias e experiências, a serem entendidos e a entenderem o outro. É sabido que a língua majoritária do Brasil é a língua portuguesa e com isso as outras línguas que são identitárias de grupos minoritários, como os surdos terminam, em muitos momentos, sendo prejudicados com a forma de comunicação.

Portanto, aprender e conhecer uma língua da qual existe um povo usuário ativo da mesma e que se faz presente, é mais que exercer uma cidadania, é respeitar a diversidade humana e aceitar que as pessoas surdas possam sim, estarem inseridas nos espaços onde todos possam se comunicar. Desde a família dos surdos até aos servidores dos órgãos públicos (surdos e ouvintes), contribuindo com o processo de aquisição e difusão da libras, favorecendo uma comunicação, especialmente, dentro da nossa instituição. Comunicação em que todos os setores possam entender e se fazerem entender em prol de uma verdadeira interação ao usarem os serviços públicos. 
(VASCONCELOS et al., 2016)

\section{Material e métodos}

O presente projeto foi fruto de uma pesquisa bibliográfica e de campo. Trabalhou-se também com a pesquisa de base exploratória, de cunho interpretativista, pois se tratou de um estudo diagnóstico, em que se procurou observar, descrever, interpretar e refletir com a perspectiva de elencar os fatos oriundos da falta de comunicação entre os surdos e ouvintes da instituição já citada. As inscrições para o curso foram realizadas por meio de editais publicados no site da instituição tendo como critério de seleção o número de ordem de inscrição.

O curso foi realizado no Instituto Federal, campus Salgueiro/PE, no período $1^{\circ} \mathrm{de}$ julho de 2015 a 30 de junho de 2016, semanalmente, com dois encontros de duas horas aulas. Dessa forma, foi elaborado um questionário e uma apostila. O questionário quantitativo foi composto por de seis perguntas (cinco objetivas e uma subjetiva), a fim de saber a quantidade de servidores que desejam aprender a Língua Brasileira de Sinais LIBRAS. Através de um questionário online, disponibilizado no e-mail institucional, identificamos um número de 36 servidores que desconhece a libras e que frequentemente atende a surdos em seus setores. Em seguida, iniciouse a elaboração de uma apostila contendo trinta e cinco páginas voltadas para o vocabulário básico da Libras como: alfabeto manual, saudações, materiais escolares, cores, verbos, adjetivos, frutas e sinais dos setores da instituição, que foi utilizado durante as aulas dos cursos.

Nesse formato foram ofertados três cursos para públicos diferentes: primeiro para os servidores; depois para os alunos e, em seguida, para os familiares dos surdos. Aplicaram-se questionários para os servidores, familiares e surdos com perguntas objetivas com uma linguagem de fácil compreensão entre a comunidade surda e os ouvintes. Para o melhor aproveitamento, foi utilizada uma apostila organizada com um vocabulário básico de Libras e com contextos pertinentes para uma comunicação, além de dicionários de Libras com autoria de Capovilla (2009).

Para isso, foram escolhidas algumas perguntas como amostragem do resultado onde o principal interesse foi saber se os servidores tinham interesse em participar de um curso de libras, sendo assim todos foram unânimes na resposta demonstrando interesse. E, logo em seguida, foram questionados sobre a importância de se aprender libras para a função ou setor que atua, obtendo diferentes respostas, como:

- $\quad$ Sempre chega surdo ao meu setor e não sei me comunicar;

- Melhorar a comunicação com alunos surdos;

- $\quad$ Por haver muitos alunos surdos na instituição, é primordial aprender Libras;

- $\quad$ Como a biblioteca é um setor comum a todos os alunos, sempre estamos atendendo alunos surdos que nem sempre vêm acompanhados dos respectivos intérpretes;

- Considerando que no meu setor ninguém sabe a Língua Brasileira de Sinais, faz-se necessária a capacitação de um dos servidores para que se possa atender ao surdo com competência;

- Meu setor está em contato direto com os alunos surdos, no entanto precisa de intérprete a todo momento;

- Sim, pois atendo e lido com os discentes e quando eles querem conversar comigo, sinto a necessidade de ter uma intérprete;

- $\quad$ Facilita a comunicação e nos inclui nesta forma de linguagem/comunicação junto às pessoas que a utilizam e

- $\quad$ Contato com alunos, durante as aulas práticas, seja extensão, ensino ou pesquisa.

Também foi realizada outra palestra tratando da autonomia da pessoa surda, assim os 
participantes puderam melhorar seu atendimento e comunicação com estes usuários. Ao final do curso os participantes que atingiram uma frequência de $75 \%$ do total da carga horária do curso e com média geral sete $(7,0)$ foram contemplados com o certificado de conclusão.
A análise o gráfico 1, e perceber-se-á quão era/é relevante a necessidade de comunicação entre ouvintes e surdos na instituição. Para confirmar os dados das perguntas acima, apresenta-se o seguinte gráfico:

\section{Resultados e discussão}

Gráfico 1: Contato com os surdos na instituição.

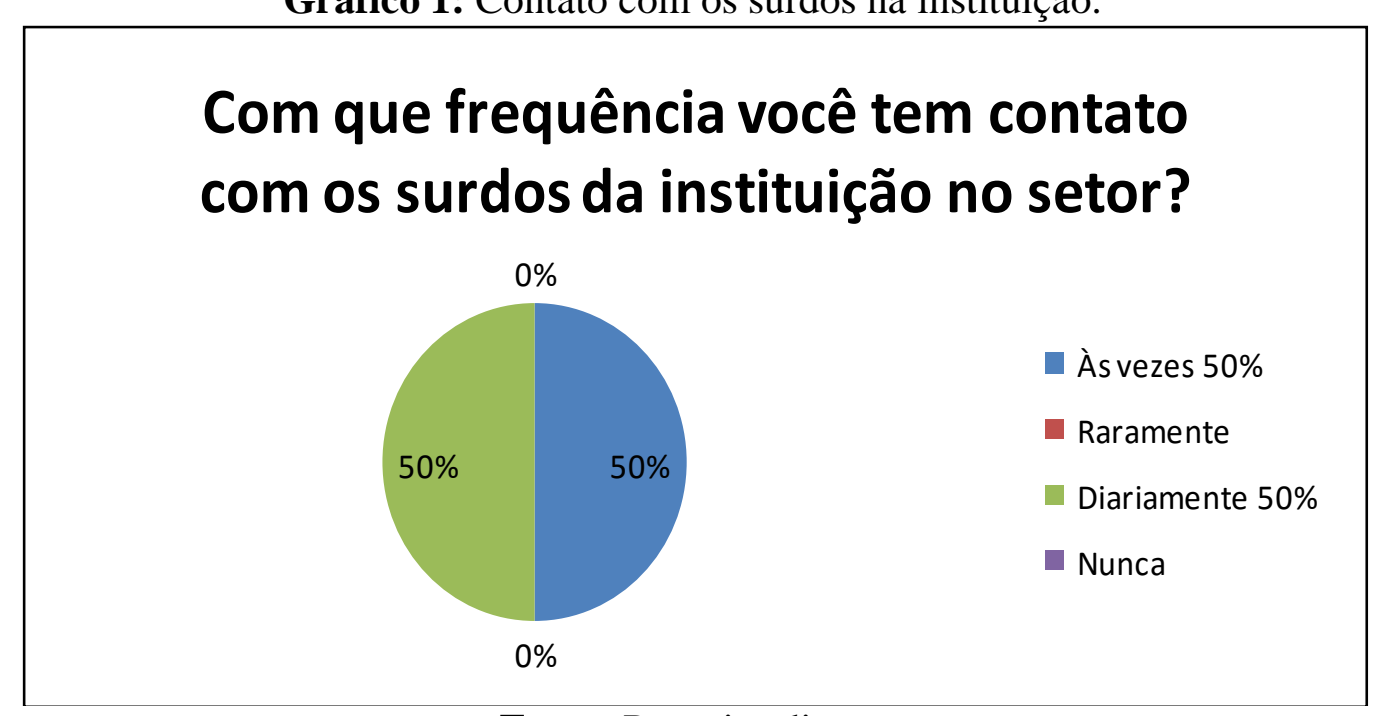

Fonte: Pesquisa direta.

Percebe-se quão era/é enorme a necessidade de comunicação entre ouvintes e surdos na instituição, pois os dados apontam que $50 \%$ dos servidores possuem contato diário com os surdos na instituição em seus setores, e os outros 50\% dizem que, às vezes, têm a presença de surdos em seus setores. Logo, podemos concluir que $100 \%$ do setores e servidores têm ou tiveram contato com surdos, mas que não sabem comunicar-se em libras.

Uma vez identificada a resposta, pode-se contrapor aos resultados das perguntas anteriores questionadas, ou seja, da falta de comunicação entre surdos e ouvintes nos diversos setores da instituição. Também, feita após os cursos, em outra avaliação, a maioria dos alunos ouvintes participantes responderam que agora tinham condições de uma comunicação básica. Visto que ao aprenderem os sinais fundamentais da libras seria possível cumprimentarem os estudantes surdos e até pedirem, caso fosse necessário, que o mesmo retornasse com a intérprete, o que antes não era possível. Isto é, o surdo chegava ao setor e nem um bom dia era sinalizado, ou qualquer outro tipo de comunicação.

Era/É óbvio a necessidade de uma comunicação com os estudantes surdos, pois sempre que se tentava uma comunicação com os mesmos, só acontecia através dos intérpretes e, na ausência desse profissional, muitas vezes não se realizava a comunicação. Nos relatos dos surdos, após a conclusão dos primeiros cursos, quando os mesmos foram questionados como estavam percebendo os resultados do curso, eles se manifestaram dizendo que ao irem ao setor pedagógico ficaram surpresos e ao mesmo tempo felizes, pois uma técnica em assuntos educacionais conseguiu, naquele espaço, se comunicar em libras com eles. A servidora, mesmo com uma comunicação elementar e se apoiando do alfabeto datilológico, perguntou e respondeu aos surdos sem o auxílio do intérprete. São resultados pequenos como esses, 
porém significativos para todos os envolvidos, principalmente para os surdos, uma vez que eles, a todo momento, sinalizam que é gratificante receber um bom dia, uma boa tarde na sua língua ao se dirigir as pessoas, sem causar constrangimento às mesmas por não saberem libras.

Outro resultado relevante foi em entrevista concedida a jornalista do Campus: um dos pais (uma mãe) relatou que é uma alegria enorme conseguir se comunicar com o filho e entendê-lo melhor, saber que entre ambos pode ser dito tudo que se quiser dizer, pois era uma preocupação por ver seu filho sozinho e ninguém lhe entender e isso gerava uma tristeza muito grande. Tristeza que, às vezes, deixava-a com sentimento de culpa, resultando em reflexões como o que tinha feito de errado?! Depoimentos como os dessa mãe existem e ainda irão existir por um bom tempo na sociedade. Muitos surdos hoje conseguem uma autonomia e uma superação mais na sociedade do que dentro da própria família. Enquanto o ouvinte recebe o apoio para ser autônomo desde tenra idade pelos familiares, o surdo recebe dos seus familiares a insegurança, o medo e a opressão na sua língua. Muitas vezes não é nem reconhecido enquanto sujeito, cidadão, pois a voz infelizmente, ainda é para muitos, a condição essencial para o exercício da cidadania e a ausência dela causa todas estas lacunas na vida de uma criança surda na família de ouvintes. Realidades como estas precisam de mudanças significativas. A superproteção que as famílias demonstram terminam subestimando a capacidade do surdo, uma inversão de valores intelectuais para valores da língua oral, ou seja,

\section{Conclusões}

Os cursos foram realizados por meio do projeto de pesquisa intitulado: A comunicação entre ouvintes e pessoas surdas através da Libras nos espaços públicos - curso acessibilidade.

Foi possível perceber através dos participantes que o curso atingiu seus objetivos dentro das atividades propostas e conseguiu através da experiência exitosa oportunizar tanto se não fala e não escuta não tem a mesma condição de aprendizagem que os ouvintes, isso é gerado por falsas concepções históricas e falta de informações aos pais.

Após essa análise, conseguiu-se atingir os objetivos, porque dos sessenta cursistas inscritos nos três cursos, tivemos quarenta e quatro que concluíram com êxito. Enfatizando que o curso para os familiares finalizou com dezenove pessoas. Isso mostra a relevância do projeto para a comunidade. Um projeto que trabalha não só o conhecimento da língua, mas a sensibilidade e oportuniza o outro a conhecer as especificidades que estão presentes no dia a dia da instituição.

Assim sendo, este projeto contribuiu com a difusão da libras não só no Instituto Federal - Campus Salgueiro, mas para toda a comunidade. Com a realização do curso para familiares foi possível perceber a alegria e emoção de alguns pais ao aprenderem a se comunicar com seus filhos efetivamente. Após as aulas práticas, foi possível notar como foi significativo aos setores da instituição ter pessoas que conseguem se comunicar usando o básico da Língua Brasileira de Sinais. Como também a sensibilização da necessidade de aprender essa língua e de se comunicar com as pessoas surdas a sua volta. As palestras realizadas atingiram não só as pessoas envolvidas no projeto, mas os interessados da área que foram até o Campus participar e discutir a temática. Os benefícios até então promovidos têm um viés da construção de um cidadão crítico e que respeita as diferenças existentes.

ao bolsista como a todos envolvidos um momento de reflexão sobre o processo de inclusão e exclusão que a falta de conhecimento da libras causa. As instituições públicas bem como o IF Sertão-PE precisam respeitar a diversidade linguística e oportunizar em seu meio a difusão das línguas existentes e utilizadas pelos estudantes, neste caso específico, os surdos. 
As políticas de inclusão que tratam sobre a libras como meio legal de comunicação e o acesso a informação através da mesma, ainda não é suficiente para que as posturas das pessoas envolvidas nas diversas ações na sociedade se preocupem em garantir de fato o que se estabelece as leis e as políticas de inclusão. Nesta perspectiva, pode-se ousar a dizer que o projeto apresenta como principal relevância o caráter de cunho reflexivo e ao mesmo tempo de intervenção, pois mostrou o quão foi pertinente para a comunidade e que projetos deste tipo precisam e devem ser apoiados nas instituições, pela sua importância social e de inclusão.

$\mathrm{O}$ curso fomentou o desejo em todos de continuar se comunicando, e isso é de certa forma um dos objetivos alcançados, pois se sabe que uma língua não se aprende em um curso de quarenta horas, mas muito mais na convivência e na interação com os usuários desta língua. Uma vertente de diálogos e de expectativas em aprender uma língua, aprender a compreender os usuários desta língua e saber quais seus costumes e valores culturais.

Também foi possível neste pequeno espaço de tempo aguçar essas reflexões nos participantes, que trouxeram um grande aprendizado $\mathrm{e}$ respeito às diferenças. A comunicação entre ouvintes e surdos nos espaços públicos precisa ser referência para outras instituições que prestam serviços aos usuários da libras e que estão, mesmo que inconscientemente, desrespeitando a língua, a cultura e a identidade surda ao ignorá-la na prestação dos serviços. E, o mais importante, de manter o contato com os surdos da instituição através de um oi, de um bom dia e de um olá sinalizado, que já contribui para todo processo de respeito às diferenças linguísticas e sociais.

\section{Referências}

BRASIL. Ministério da Educação. Secretaria de Educação Especial. Lei No. 10.436, de 24 de abril de 2002. Dispõe sobre a Língua Brasileira de Sinais - LIBRAS e dá outras providências.

Ministério da Educação. Secretaria de Educação Especial. Decreto $\mathbf{N}^{\mathbf{0}} \mathbf{5 . 6 2 6}$, de 22 de dezembro de 2005. Regulamenta a Lei $\mathrm{N}^{\circ}$ 10.436, de 24 de abril de 2002.

CARVALHO, R. E. Escola inclusiva: a reorganização do trabalho pedagógico. Porto Alegre: Mediação, 2008.

CAPOVILLA, F. C.; RAPHAEL, W. D. Dicionário Trilíngue da Língua de Sinais Brasileira. São Paulo: UNESP, 2008.

LODI, A. C. B.; LACERDA, C. B. F. (org.). Uma escola, duas línguas: letramento em língua portuguesa e língua de sinais nas etapas iniciais de escolarização. Porto Alegre: Mediação,2014.

LONGMAN, L. V. Memórias de Surdos. Recife: Massangana, 2007.

SOARES, M. A. L. A educação do surdo no Brasil. Campinas, SP: Autores Associados, 2005. 